\title{
Improving access to transient elastography in Canada will need more than evidence-based guidelines and technical health assessment
}

\author{
Kevork M Peltekian MD FRCPC
}

$\mathrm{I}^{\mathrm{n}}$ n the current issue of the Journal, Aljawad et al (1) (pages 373-376) focus on the availability of transient elastography in Canada. This is an important clinical care delivery issue for all gastroenterologists, hepatologists and every practitioner who provides care for individuals with suspected or confirmed liver disease. Transient elastography (Fibroscan, Echosens, France) quantifies hepatic fibrosis using mechanical wave generated by a special transducer. The principle is simple: the speed of a propagating wave through the liver is influenced by the stiffness of the tissue - the stiffer the liver, the faster the wave passes through.

Despite the availability of this technology for more than a decade, the uptake of this noninvasive technology in North America has lagged behind Europe and Asia. In the meantime, the technology has evolved from using mechanical wave to using sound waves with the acoustic radiation force impulse imaging (ACUSON S2000 Virtual Touch Tissue Quantification, Siemens Healthcare, USA) and shear wave elastography (ShearWave Elastography, Supersonic Imaging, France). Now there is also magnetic resonance elastography (Resoundant, USA), in which a mechanical vibrator is used on the surface of the patient's body, creating shear waves that travel through the patient's liver. An imaging acquisition sequence measures the velocity of the waves providing a quantitative three-dimensional map of the hepatic stiffness.

So why are we behind in bringing this technology to our patients? Introducing new medical devices into the Canadian health care system entails complex regulatory, reimbursement and procurement processes (2). Hospitals, regional health authorities and provincial governments use more formalized committees, more sophisticated metrics and have more influence on the procurement process. These changes are in response to pressures to contain costs, and emphasize clinical outcomes and system efficiencies. Often these processes include multiple steps to quantify burden of disease, unmet needs, and both clinical and economic values. For transient elastography, all of these metrics have been evaluated.

Hepatic fibrosis is integral to chronic liver disease. Globally, alcohol consumption, hepatitis $\mathrm{B}$, hepatitis $\mathrm{C}$ and nonalcoholic fatty liver disease are important causes of morbidity and mortality. The burden of overall hepatic fibrosis in Canada is not known; however, it is estimated to be massive. Furthermore, at least for hepatitis C, the burden of chronic liver disease is projected to swell with the increasing prevalence of end-stage liver disease and hepatocellular carcinoma (3).

Canadian investigators have been leaders in studying alternatives to liver biopsy for staging the extent of hepatic fibrosis, publishing multiple studies on transient elastography involving patients from coast to coast (4). The Canadian Association for the Study of Liver was also ahead of the curve in publishing guidelines regarding noninvasive liver fibrosis assessment (5). Only recently, the European Association for the Study of the Liver and the Asociación Latinoamericana para el Estudio Del Hígado jointly issued evidence-based clinical practice guidelines regarding the use of noninvasive tests for evaluation of liver disease severity (6). The American Association for the Study of Liver Diseases maintains liver biopsy as the gold standard with acknowledgement that the procedure is invasive, costly, and involves a small risk for bleeding and death.

Although transient elastography performs well in identifying individuals with cirrhosis in a reproducible fashion, it has shortcomings including the machine's cost, inability to discriminate between intermediate stages of fibrosis and poor performance on obese patients. Liver biopsy is probably not that precise either, especially in staging of fatty liver disease. The main advantage of transient elastography is in being able to screen for patients at greatest risk and in need of referral or treatment - after all, one cannot biopsy every patient with chronic liver disease. Through transient elastography, one can stratify patients who do not need treatment and do not need to be referred to a specialist.

The device was approved by Health Canada in July 2009. Yet, in a survey of Canadian physicians who manage patients with chronic liver diseases, almost one-half of respondents still utilize liver biopsy to stage fibrosis in patients instead of noninvasive methods, particularly transient elastography (7). The Canadian physicians cited limitations in access to and availability of the noninvasive methods as a significant barrier. They also raised the need for clinical guidelines and a better reimbursement policy to implement noninvasive tools to assess liver fibrosis. Interestingly, the FibroScan device was only approved by the United States Food and Drug Administration in April 2013, a decade after it first arrived in Europe. In the United States, transient elastography already received a current procedural terminology code in January 2015 (91200), and is reimbursed by Medicare at $\$ 134.80$ per outpatient test.

A health technology assessment of transient elastography has been completed in Canada, confirming it is less expensive than liver biopsy and recommending a systemic implementation of transient elastography as a noninvasive assessment of liver fibrosis (8).

Therefore, all of the decision-making elements are available, but the key issue for access to transient elastography and its availability for in-hospital use is funding through public programs rather than out-ofpocket payment for the general public. Capital represents the total pool of funds expended by hospitals and health authorities to acquire and upgrade technology or equipment. Canada currently spends at least $\$ 8.8$ billion on health care capital annually - a relatively small proportion of health care cost - but capital represents the fastest growing component of health system spending (9). Access to capital in the healthcare system is largely controlled by provincial governments. Governments manage capital through direct approval of capital projects, and by controlling operating funding. Theoretically, government planning should also lead to greater equity in capital distribution based on value; however, variability in political priorities and agendas usually affect the decision-making process.

Department of Medicine and Surgery, Dalhousie University and Division of Digestive Care $\mathcal{G}$ Endoscopy, Queen Elizabeth II Health Sciences

Centre, Nova Scotia Health Authority, Halifax, Nova Scotia

Correspondence: Dr Kevork M Peltekian, Dalhousie University and Division of Digestive Care Eु Endoscopy, Queen Elizabeth II Health Sciences Centre, Nova Scotia Health Authority, 1276 South Park Street, Halifax, Nova Scotia B3H 2Y9. Telephone 902-473-7783,

fax 902-473-2783,e-mail kevork.peltekian@nshealth.ca

Received and accepted for publication September 8, 2015 
It is time to have more gastroenterologists and hepatologists with expertise in health care service delivery. The provision of high-quality, affordable, health care services is increasingly difficult. Due to the complexities of health care services and systems, understanding costs, quality, accessibility, delivery, organization, financing, and outcomes of health care services are key to informing government officials, insurers, providers, consumers, and others making decisions about healthrelated issues.

\section{REFERENCES}

1. Aljawad M, Sirpal S, Yoshida EM, Chandok N. Transient elastography in Canada: Current state and future directions. Can J Gastroenterol Hepatol 2015;29:373-6.

2. Husereau D, Arshoff L, Bhimani S, Allen N. Medical device and diagnostic pricing and reimbursement in Canada. Edmonton (AB): Institute of Health Economics; 2015.

3. Myers RP, Krajden M, Bilodeau M, Kaita K, Marotta P, Peltekian K, Ramji A, Estes C, Razavi H, Sherman M. Burden of disease and cost of chronic hepatitis C infection in Canada. Can J Gastroenterol Hepatol 2014;28:243-50.
4. Myers RP, Elkashab M, Ma M, Crotty P, Pomier-Layrargues G. Transient elastography for the noninvasive assessment of liver fibrosis: A multicentre Canadian study. Can J Gastroenterol 2010;24:661-70.

5. Myers RP, Shah H, Burak KW, Cooper C, Feld JJ. An update on the management of chronic hepatitis C: 2015 Consensus guidelines from the Canadian Association for the Study of the Liver. Can J Gastroenterol Hepatol 2015;29:19-34.

6. EASL-ALEH Clinical Practice Guidelines: Non-invasive tests for evaluation of liver disease severity and prognosis. J Hepatol 2015;63:237-64.

7. Sebastiani G, Ghali P, Wong P, Klein MB, Deschenes M, Myers RP. Physicians' practices for diagnosing liver fibrosis in chronic liver diseases: A nationwide, Canadian survey. Can J Gastroenterol Hepatol 2014;28:23-30.

8. Steadman R, Myers RP, Leggett L, Lorenzetti D, Noseworthy T, Rose S, Sutherland L, Clement F. A health technology assessment of transient elastography in adult liver disease. Can J Gastroenterol 2013;27:149-58

9. Capital spending in healthcare: A missed opportunity for improvement? Ottawa: Canadian Foundation for Healthcare Improvement, 2013. <www.cfhi-fcass.ca/Libraries/Reports/CapitalSpending-Brown-E.sflb.ashx> (Accessed September 7, 2015). 


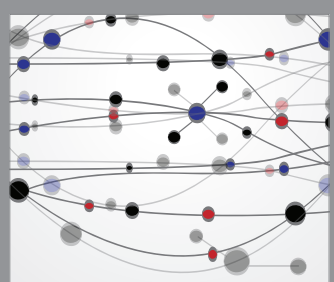

The Scientific World Journal
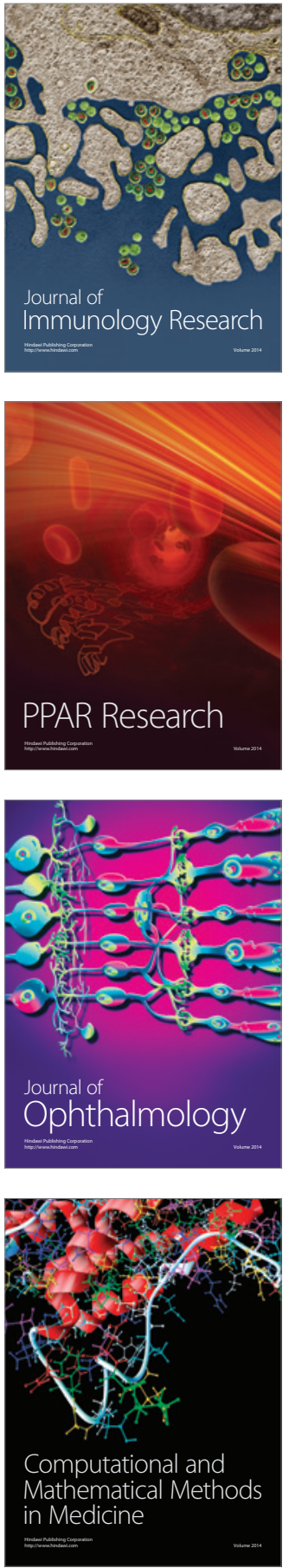

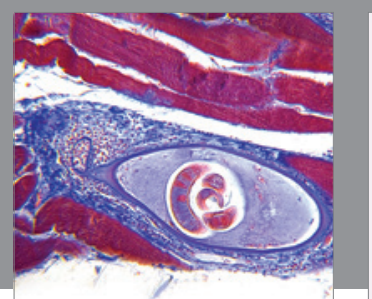

Gastroenterology Research and Practice

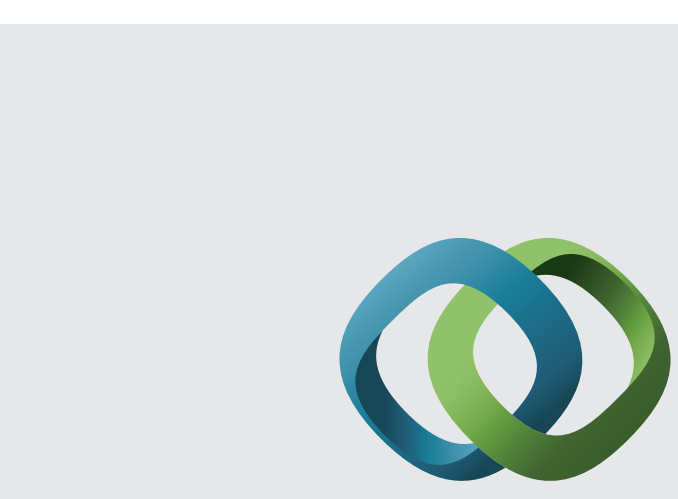

\section{Hindawi}

Submit your manuscripts at

http://www.hindawi.com
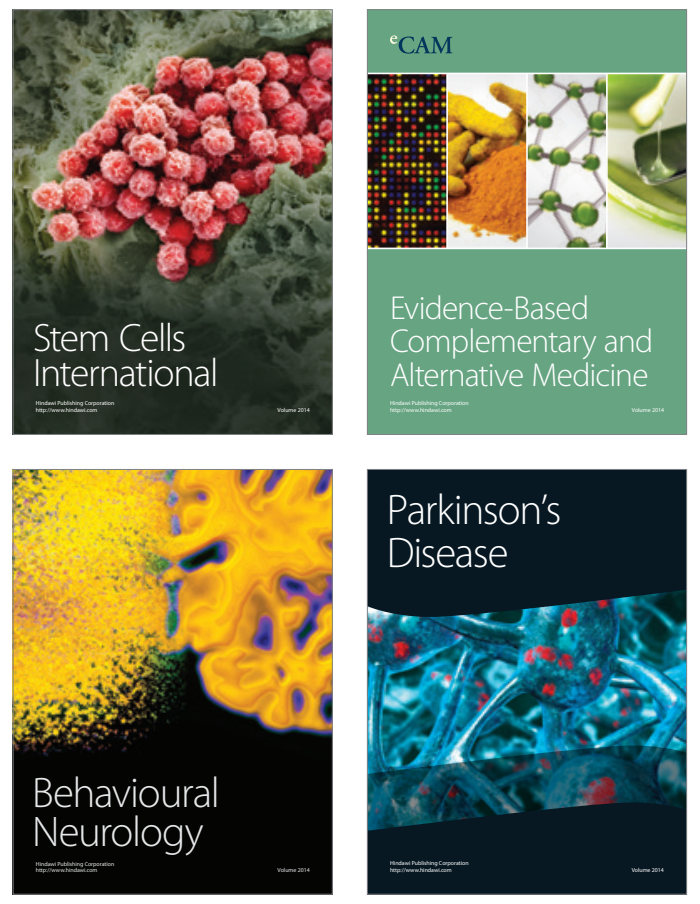
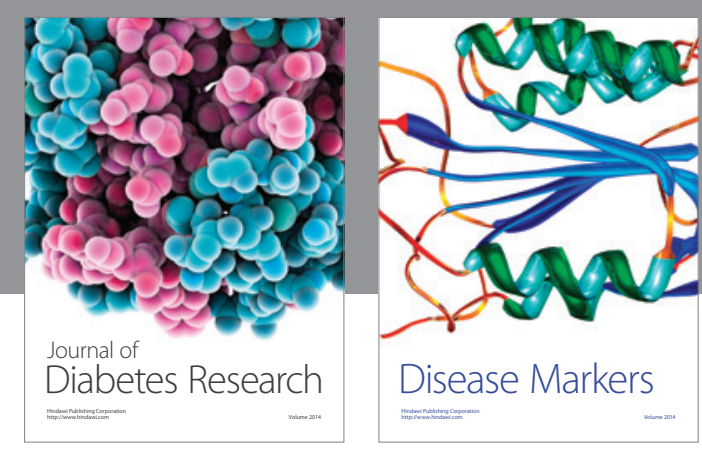

Disease Markers
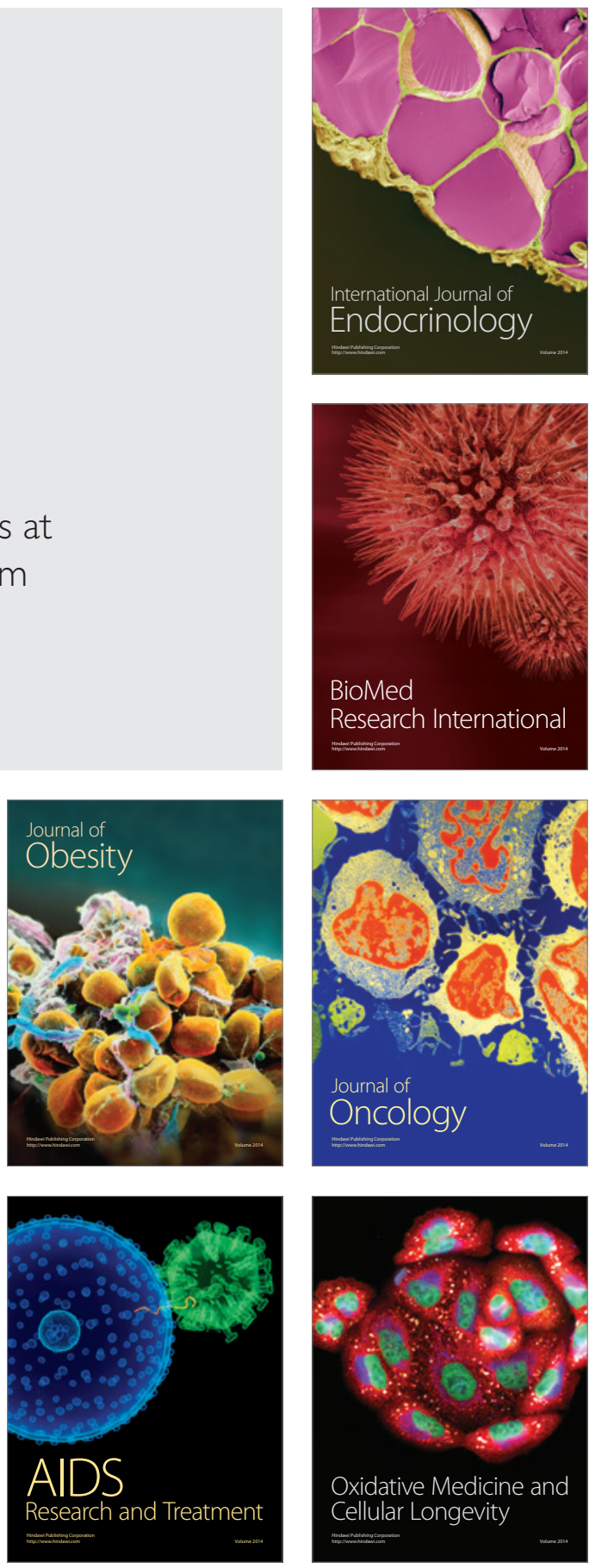